\title{
Regulatory Acceptance and Use of 3R Models: a Multilevel Perspective
}

\author{
Marie-Jeanne W. A. Schiffelers ${ }^{1}$, Bas J. Blaauboer ${ }^{2}$, \\ Coenraad F. M. Hendriksen ${ }^{3}$, and Wieger E. Bakker ${ }^{1}$ \\ ${ }^{1}$ Utrecht University School of Governance, Utrecht, The Netherlands; ${ }^{2}$ Institute for Risk Assessment Sciences, Utrecht \\ University, Utrecht, The Netherlands; ${ }^{3}$ Netherlands Vaccine Institute \& Department of Animals in Science and Society, \\ Faculty of Veterinary Medicine, Utrecht University, Utrecht, The Netherlands
}

\begin{abstract}
Summary
The importance placed on risk avoidance in our society has resulted in a broad range of regulations intended to guarantee safety of products such as pharmaceuticals and chemicals. Many of these regulations rely on animal tests. As a result, about $25 \%$ of the animal experiments in Europe are done for regulatory purposes. There are many initiatives that aim to replace, reduce, or refine laboratory animal use, but the regulatory acceptance and use of $3 R$ models lags behind. The central question of this study is: "Which variables influence the regulatory acceptance and use of $3 R$ models and in what way?" Regulatory acceptance is seen as one of the biggest hurdles $3 R$ models face, but the rationale behind this is still underexplored. This study is an approach to filling that gap by combining opinions from experts in the field with literature on technology acceptance and risk regulation, resulting in a model of the variables that determine the process of the regulatory acceptance and use of $3 R$ models.
\end{abstract}

Keywords: 3R models, regulatory acceptance, influencing variables, multilevel perspective, $3 R$ acceptance model

\section{Introduction: the problem of regulatory 3R acceptance}

"...we have again and again encountered instances of long delay in the application of existing knowledge to the improvement of experimentation... Delays of this kind may be regarded as a sort of inertia, or rigidity, the maintenance of a habit (positive or negative) long after information is available for its correction. In the individual organism, rigidity of this kind has been shown to be associated with isolation, or lack of communication between central nervous mechanisms... It is entirely reasonable to expect a similar relationship at the sociological level..." (Russell and Burch, 1959)

This quote from the founding fathers of the 3R Principle (i.e., to Replace, Reduce, and/or Refine laboratory animal use where possible) perfectly illustrates the problem $3 \mathrm{R}$ models ${ }^{1}$ have faced ever since the principle was introduced in 1959 , namely the slow acceptance of these "new" technologies. Even though numerous 3R models have been developed over the past decennia the regulatory acceptance and use of these models, i.e., to prove the quality and safety of chemical compounds, pharmaceuticals, and biological products (e.g., vaccines), lags behind.
Though new technologies often face a hard time in getting accepted, numerous innovations have been able to cross the existing barriers and considerable research has been dedicated to the process of innovation transfer. This study makes use of the general notices on technology transfer to better comprehend the slow process of regulatory acceptance and use of $3 \mathrm{R}$ models and the variables that drive or hamper this process. In addition, it examines ways to facilitate the process.

We live in a society that is confronted with many products that might pose a risk to our health and to the environment. To minimize the possibility of adverse effects from these products, a complex system of rules and regulations has been designed. In the EU alone, there are more than 800 laws, regulations, directives, and other documents regulating product safety and quality (De Leeuw, 2004). The requirements determine the endpoints that products must be tested on by manufacturers and, occasionally, by regulatory authorities as well before they are released for commercial purposes (e.g., toxicity, efficacy, etc.). Animal testing is a "traditional" element of these product assessment procedures and accounts for at least $25 \%$ of the animal experiments conducted within the European Union (Anon., 2010).

Now, however, many developments focus on alternative testing strategies and aim to move away from animal testing.

Received January 31, 2012; accepted in revised form April 12, 2012

${ }^{1}$ All procedures which can completely replace the need for animal experiments, reduce the number of animals required, or diminish the pain or distress suffered by animals. 
Those developments include the many in vitro models for R\&D purposes of new drugs or chemical compounds. The increasing number of $3 \mathrm{R}$ models available for regulatory purposes offer the possibility for manufacturers and regulators to choose the method they perceive as most suitable in those cases where the regulatory requirements offer discretionary space. ${ }^{2}$ Furthermore, there are many $3 \mathrm{R}$ partnerships, both at the national and the supranational level, in which regulatory testing is part of the agenda. In addition, there is horizontal European legislation to protect animals used for scientific purposes (Directive 2010/63/EU), which states that 3R models shall be used wherever possible (European Commission, 2010). ${ }^{3,4}$ So in those cases where regulatory product requirements describe a $3 R$ model or a battery of $3 \mathrm{R}$ models and the conventional animal model and offer discretion to regulators and industry to choose a testing method, they should, in light of this Directive, decide to use the $3 \mathrm{R}$ option. Finally, the objections to regulatory animal testing from an animal welfare, an economic, and a scientific perspective are on the increase, as will be elucidated below. These objections make regulatory animal testing an important area to evaluate in terms of the $3 \mathrm{R}$ principles. All in all, there are many reasons to move away from regulatory animal testing and toward the use of alternative models.

However, despite all these initiatives, the heavy reliance on animal models for safety and quality testing purposes is very persistent. Most stakeholders in the field of alternatives to animal testing know of $3 \mathrm{R}$ models that were developed up to 30 years ago and still are not accepted by regulatory authorities or used by manufacturers for regulatory purposes.

With regard to the $3 \mathrm{Rs}$, most studies focus on the technical possibilities and limitations of specific methods. Research concerning the regulatory process and the ultimate use of $3 R$ models is limited (Freriks et al., 2005). ${ }^{5}$ This study aims at filling that gap by answering the following central question: "Which variables influence the acceptance and use of $3 R$ models for product regulation purposes and in what way?" It offers a profound overview of the variables influencing this process.

To demarcate the research area, we start by defining regulatory acceptance and use:

Regulatory acceptance:

refers to the written or unwritten adoption of testing strategies by regulatory authorities. Regulatory acceptance in this context is defined as the formal adoption of a (validated) test method by a regulatory agency/authority. Depending on the product sector, regulatory acceptance can be accomplished at a national, a European, and/or a global level.

Regulatory use:

refers to the actual uptake of a method by a regulatory authority or a manufacturer for quality and/or safety testing purposes. This step is often also referred to as implementation. In the field of policy science, however, implementation would cover the whole process from the initial intention to work towards alternatives to the actual use. For this reason the term regulatory use is preferred in the context of this article.

Regulatory use for the purpose of this paper is looked upon as a function of regulatory acceptance in which the level of acceptance strongly determines the level of regulatory use. Although there are some cases in which regulatory use has anticipated regulatory acceptance or occurred without formal regulatory acceptance, these situations are viewed as isolated cases.

\section{Investigative approach}

In order to answer the central question, this paper elucidates the process of acceptance and use of new technologies such as $3 \mathrm{R}$ models and offers an overview of variables that influence this process. The current study builds on our earlier work (Schiffelers et al., 2007) and intends to bring the discussion a step further by systematically describing the process of acceptance and use and by presenting the " $3 \mathrm{R}$ Acceptance Model," which contains an overview of the variables that are observed to influence the process of acceptance and use. For this purpose a combination of theoretical and empirical factors is described. The theoretical variables derive from theoretical perspectives on risk regulation and the acceptance of innovations. The empirical findings partly derive from the earlier work conducted in this field (Schiffelers et al., 2005, 2007). These findings were tested and updated by an additional series of ca. twenty interviews with representatives from European and US regulatory authorities, industry, and academia familiar with the subject of regulatory testing and the acceptance and use of 3Rs models.

\footnotetext{
2 The legal dictionary defines "discretion" as: The power of a judge, public official or a private party (under authority given by contract, trust or will) to make decisions on various matters based on his/her opinion within general legal guidelines.

3 Article 4 of the European Directive 2010/63/EU for the Protection of Laboratory Animals stipulates that: "Member States shall ensure that, wherever possible, a scientifically satisfactory method or testing strategy, not entailing the use of live animals, shall be used instead of an animal based procedure."

4 Being horizontal legislation (see also footnote 18), this directive applies to all product sectors that are involved in animal testing. This means that scientists, manufacturers, and regulatory authorities within these sectors have the duty to ensure that animal usage is kept to a minimum and animal health and welfare legislation is upheld.

5 Some examples of studies that focus on these stages are: NIEHS, 1997; Garthoff, 2005; Schiffelers et al., 2005; Bottini et al., 2008.
} 
Furthermore, regulatory testing was part of the agenda in a series of international meetings attended throughout the period of 2009-2011. ${ }^{6}$

The empirical findings, presented in this study are the ones the researchers came across most frequently throughout the different interviews and meetings. It must be emphasized that the type and weight of the factors might differ between geographical regions, product groups, industries, and agencies.

To clarify the process of acceptance and use of $3 \mathrm{R}$ methods for regulatory purposes the following steps are taken. First, a multilevel approach is described, which is used to explain the complex process of innovation acceptance in general and regulatory acceptance and use of $3 \mathrm{R}$ models in particular. This approach is based on the "multilevel perspective on system innovation" described in the Dutch transition literature (Rip and Kemp, 1996; Geels and Kemp, 2000; Kemp, 2010). Second, this multilevel perspective is applied to the field of regulatory acceptance and use of $3 \mathrm{R}$ models. This results in a description of the relevant variables that are considered to influence the transition towards $3 \mathrm{R}$ acceptance and use in the area of product regulation. Third, these variables will be recapitulated in the "3R Acceptance Model," which is presented and described in section 4 of this article. This model consists of the variables that are perceived to play a relevant role in the regulatory acceptance and use of $3 \mathrm{R}$ models. It makes a distinction between the variables that originate from a macro(society), meso- (institutions, organizations), and micro- (individual people and models) level. To conclude, a distinction is made between the so-called rigid variables (variables that are relatively difficult to manipulate) and the more pliable variables (Ellemers, 1976). This division is important when discussing ways to optimize the process of acceptance and use.

\subsection{The multilevel approach: an inclusive model to comprehend regulatory $3 R$ acceptance}

The process of regulatory acceptance and use of $3 R$ models is determined by a broad set of factors. In order to cover and comprehend the complex reality, the multilevel model of innovations and technology transformations is introduced.

This model offers valuable concepts for the analysis of longterm technological transitions by integrating insights from several disciplines (Geels, 2006). Such an integrative perspective is important in creating a complete picture of the dynamics of system innovations such as the transition from animal models to the 3Rs. Furthermore, it addresses the strong interlinkage between social and technical aspects in such technology transitions. A visual representation of the multilevel model was introduced by Rip and Kemp in 1996 (see Fig. 1).



Fig. 1: The multilevel model of innovation and transformation

The model specifies three different levels important to look at when analyzing system innovations, viz.:

- the micro- or niche level in which novelties are developed;

- the meso- or sociotechnical regime level, which consists of the patchwork of rules and regulations, available expertise, current practices, and connected institutions;

- the macro- or sociotechnical landscape level, which relates to elements such as the material infrastructure, existing political culture and coalitions, social values, world views, the macroeconomy, demography, and the natural environment (Kemp, 2010).

These levels will be further described and operationalized in section 3 .

Transitions come about through the interaction of processes at the three different levels. At stage 1 (see Fig. 1) innovations, like alternative test approaches, commence in niches, isolated from the existing regime. There is not yet one dominant design of the new technology, and experiments are conducted to work out the best design and "find out what users want." The networks that support the innovations are small and unstable and "the innovations do not (yet) form a threat (i.e., competing model) to the existing regime" (Kemp, 2010: 293). At stage 2, the system begins to shift and the process of change starts. "The new technology develops a technical trajectory of its own and rules begin to stabilize (e.g. a dominant design). But the innovation still forms no major threat to the regime, because it is used in specialized market niches" (Kemp, 2010: 293). Phase 3 is that of the "wider breakthrough," a result of "an accumulation of

\footnotetext{
6 - 3R symposium: Looking into the crystal ball (January, 2009, Utrecht, The Netherlands)

$-7^{\text {th }}$ and $8^{\text {th }}$ World Congress on Alternatives and Animal Use in the Life Sciences (August, 2009, Rome, Italy; and August,

2011, Montreal, Canada)

- ECVAM/EPAA workshop on The Consistency Approach for Quality Control of Vaccines - a 3Rs Opportunity (January,

2010, Brussels, Belgium)

- Workshop ICCVAM/NICEATM: 3Rs in Vaccine Potency Testing (September, 2010, Bethesda, USA)

- Conference EDQM: Quality of Medicines in a Globalized World: Dream or Reality? (October, 2010, Prague, Czech

Republic)
} 
socio-cultural, economic, ecological and institutional changes that react to each other." The new technology in this stage is in competition with the existing regime. According to this approach, system innovations come about because the developments at the different levels "link together and reinforce each other" (Geels, 2006: 176). This means that system innovations are hardly ever the result of one single factor or actor, but are the "result of the interplay between many processes and actors" (Geels, 2006: 176).

\section{Results: 3R acceptance from a multilevel perspective}

We will now go into each of the three levels, starting with the micro-level, and define the variables that are observed to play an important role at each level.

\subsection{Influences at the niche level}

At the micro-level of technological niches, 3R models are novelties designed against the background of existing (welldeveloped and established) product regulation regimes. The niches function as "incubation rooms" that protect the new technologies from the market selection mechanism. Successful innovations will eventually break through to the regime level, but:

"New technologies may remain stuck in these niches for a long time (decades), when they face a mismatch with the existing regime and landscape." (Kemp, 2010: 293)

And this is exactly what can be observed for many $3 \mathrm{R}$ models, as will be described in this section. At the micro-level of niches, several factors can be observed that influence the process of regulatory acceptance and use of $3 \mathrm{R}$ models, such as the potential of $3 R$ models (see 3.1.1) versus their limitations (see 3.1.2), the education and experience of stakeholders involved with these models (see 3.1.3), and the validation process (see 3.1.4).

\subsubsection{The promising potential of $3 R$ models...}

The 3R Principle was first introduced by Russell and Burch in 1959 in their revolutionary work The Principles of Humane Experimental Technique. Since then, many 3R models have been developed and the 3R Principle is still gaining ground.

"The motive for developing and incorporating the $3 R s$ is usually neither altruism nor public relations. Rather, methodological improvements are sought as a means of overcoming the technical limitations inherent in current animal models. To practicing scientists, these more elegant and relevant methods represent technical progress and are considered to be additional or advanced, rather than alternative, methods... Such methods are often more valid and more reliable than those traditionally used in regulatory testing." (Richmond, 2002)
This quotation of Richmond, former head of the Home Office's Scientific Procedure division, illustrates the potential 3R models have from a scientific perspective. The models tend to have a more solid scientific base than the conventional animal models. ${ }^{7}$ Most of the animal models were developed decades ago and are the product of a process of trial and error. They often lack formal validation and some show problems of high variability in test results and an extrapolation gap between the animal model and the human being. In addition, they frequently are a concern in terms of animal welfare and are often time consuming in comparison to the alternative model.

An example is the case of rabies vaccines where the regulatory community and industry still rely on the 60-year-old animal-based potency test (NIH test). This test is flawed for several reasons. It is widely agreed upon that the test is highly variable in its results, with a variety of up to $400 \%$ (Krämer, 2010). In addition, it causes severe pain and distress to the animals involved, and the fact that the infected animals actually develop rabies is a safety risk to lab staff as well. Finally, performing the animal model takes more time than the proposed alternatives. Over time several 3R models have been developed, such as full replacement antibody quantification tests and serological tests that still use animals but can be considered a big gain in terms of reduction and refinement when compared to the NIH test. Both 3R alternatives show less variability in their test results and are a major improvement in terms of animal welfare. Nevertheless, these innovations have never managed to dethrone the $\mathrm{NIH}$ test for regulatory potency testing purposes.

So even in cases where the scientific value of the animal model is questioned and $3 \mathrm{R}$ options have been available for quite some time, 3R models might face difficulties in breaking through, as is illustrated by the rabies case.

\subsection{2 ...versus the refractory reality}

Many 3R models are already quite extensively used for R\&D of (new) products but, as mentioned, they often face a hard time in getting accepted at the regime level of existing rules, regulations, and testing practices, and so they fail to become genuine rivals to the respective conventional animal models, let alone to become the leading paradigm in risk assessment procedures. According to Geels, a radically new technology has "... a hard time to break through since it does not solely involve a change in the technology but because regulations, infrastructure, user practices and maintenance networks are aligned to the existing technology" (Geels, 2002: 1258). This means that the more drastic the change when compared to the animal model, the more

\footnotetext{
${ }^{7}$ Here it should be noticed that for the sake of reducing complexity the $3 R$ models are being referred to as one package of innovations. In reality, however, 3R models consist of a wide range of techniques, varying from techniques that still rely on animal models but to a lesser extent to models that fully replace the animal model.
} 
difficulties the $3 \mathrm{R}$ model is likely to face in terms of regulatory acceptance. Replacement models, in fact, embody a more radical change to the existing regime than reduction and refinement models, which are generally still based on the design of the conventional animal model. However, even refinement methods such as social housing of rats can face stumbling blocks when it comes to regulatory acceptance, as is the case in some OECD guidelines (Verwer et al., 2007).

The tedious process of acceptance is, among other things, the result of the fact that $3 \mathrm{R}$ models (especially replacement models) face the drawback that they lack the ability of animal tests to mimic the entire organism. This means that a $3 \mathrm{R}$ model generally is not a stand-alone model but just one part of the puzzle, and so a combination of tests is needed to replace an animal method. On top of that, the researchand development-base for really novel approaches becomes smaller. It seems that the low hanging fruit have been picked, and scientists now face the challenge of developing models for the more difficult endpoints like carcinogenicity (ability of a compound or product to cause cancer), systemic toxicity (ability of a compound to induce organ toxicity), and reproductive toxicity (ability to harm the developing fetus or organs of reproduction). The problem here is that the development of these more complex alternatives "...is bound up with the progress of science in developing a deeper understanding of fundamental biological processes" (Rudacille, 1999). On the other hand, science is proceeding and thereby offering new possible approaches such as omics technologies in toxicity testing and physico-chemical methods in vaccine quality control.

\subsubsection{Past education and former experiences}

An important variable of influence on the level of acceptance of $3 \mathrm{R}$ models lies in the past education of the stakeholders that have to work with the models. In large part, the current generation of regulators was educated some 20-30 years ago when the credo still was "in vivo veritas" (Schiffelers et al., 2007: 274). This education remains very influential on the level to which stakeholders feel comfortable with certain models. To gain trust in new techniques it is important to be able to work with them and gain experience with the way they function. ${ }^{8}$ Education and training are therefore important aspects in the acceptance and use of 3Rs models. Only positive experiences with the new techniques can bend old convictions towards the 3 Rs.

Due to their education and greater exposure to $3 \mathrm{R}$ models, the new generation of regulators most likely will incline more towards in vitro methods (Schiffelers et al., 2007). This development can, for example, already be observed in Europe in the area of biologicals, where several Official Medicine Control Laboratories (OMCL's) have developed models to replace, reduce, or refine conventional animal models.

\subsubsection{The validation challenge}

A final, but crucial, step on the way to the implementation of alternative methodologies is the need to validate these tests. In general, regulators will accept alternative toxicity testing methods only after they have been scientifically validated. This means that they have been shown to be reliable (reproducible) and relevant for their intended purpose. ${ }^{9}$ If the test is going to be used for regulatory purposes its robustness has to be demonstrated to the regulatory authorities (EPAA, 2007). Validation, therefore, can be regarded as a sort of "gate keeper" to prevent "immature" tests from entering the regime level. According to the OECD, formal validation "contributes strongly to the international acceptance of any proposed test method" (Spielmann, 2000). As a result, the OECD has indicated that in vitro toxicity studies can be accepted for regulatory purposes only after a successful experimental validation study.

But demonstrating the validity of a method to regulatory authorities is a tedious process. And every single step of a formal validation study brings about many challenges in terms of time, costs, and motivation ${ }^{10}$ (Spielmann, 2000). One of the main challenges is that the validity of a $3 \mathrm{R}$ method often is evaluated by comparing it with the conventional in vivo model, even though the $3 \mathrm{R}$ model is in most cases incomparable to the conventional model, and the animal model might generate highly variable results or might be of questionable relevance. This makes it almost impossible to demonstrate correlation between the conventional and the new model, thereby creating a major hurdle in getting the new model through the validation process. On top of this, validation is a confusing concept, meaning different things to different people and under different circumstances. This has led to some situations where a validation study raised more questions than it answered (Metz et al., 2002).

Although validation is an important step, it is not indispensable for regulatory acceptance. In some cases $3 \mathrm{R}$ tests have been accepted by regulators without being formally validated. This happened, for example, with an in vitro dermal absorption test. European industry in this case submitted in-house validation data to the OECD, and after peer review and international discussions, an OECD Technical Guideline for in vitro dermal absorption testing was adopted (Liebsch and Spielmann, 2002).

Conversely, validation does not automatically lead to regulatory acceptance. This often is a consequence of insufficient consulting of regulatory authorities in the phase of validation and failing to take the right criteria on board to validate the test for regulatory purposes. Therefore, an early involvement of regulatory authorities when validating a method is often considered a critical success factor (Bottini et al., 2008).

\footnotetext{
8 It must be noted here that risk assessors can also be developers of $3 R$ models themselves, as can be observed in within the European Official Medicine Control Laboratories (OMCL's). In these cases this argument can be discarded.

9 http://alttox.org/ttrc/tox-test-overview/

10 Validation is often perceived as applied science by scientists.
} 


\subsection{Influences at the meso-level of risk regulation regimes}

The meso-level is formed by the sociotechnical regime, which is at the heart of the transition scheme. The term "regime" refers to the deeply rooted collective memory of stakeholders of dominant practices. It consists of a semi-coherent set of rules, search heuristics, or paradigms relevant to that domain, giving it stability, orientation, and guidance in the decision-making (Kemp, 2010; Geels, 2002, 2006). Stakeholders within these regimes, such as regulatory authorities and industry, act according the "logic of appropriateness," meaning that they do what they think is expected, legitimate, and rightful in the role they fulfill (Bakker, 2001). And since regimes are subject to pressure from both the macro- and the micro-level, stakeholders within these regimes will have to cope with these pressures in an appropriate manner.

"Faced with these pressures, regime actors will typically opt for change that is non-disruptive, ..., which leads them to focus their attention to system improvement instead of system innovation" (Kemp, 2010:293).

At the meso-level, several fundamental aspects are identified that are key to understanding the process of acceptance and use of $3 \mathrm{R}$ models for regulatory purposes, such as the leading technological paradigm (see 3.2.1), diverse risk regulation regimes (see 3.2 .3 ), the informational asymmetry between regulators and industry (see 3.2.3), and transition costs (see 3.2.4).

\subsubsection{The animal model is the technological paradigm}

As mentioned, the "regime" level refers to the dominant practices consisting of a semi-coherent set of rules. Giovanni Dosi in this context refers to the technological paradigm. Dosi's paradigm is defined as a set of pieces of knowledge, both practical and theoretical, know-how, methods, procedures, physical devices, and equipment, as well as experience of successes and failures. It includes "the 'perception' of a limited set of possible technological alternatives and of notional future developments" (Dosi, 1982: 152). Dosi states that technological paradigms embody strong decrees of technological changes that need to be followed or neglected. As such, technological paradigms have a powerful exclusion effect. When a technological trajectory ${ }^{11}$ is powerful, it might be especially difficult to change from one trajectory to another (Dosi, 1982).

Regulatory animal testing is such a powerful technological trajectory. Organizations around the world have been using animal models for many decades to prove the quality or safety of products. This deeply rooted experience with animal tests has provided these models with the status of "gold standard." Most regulators will only accept an alternative test if it will allow them to assess a compound or product in a way similar to the gold standard. As a result, animal-based regulatory testing remains, as researcher Thomas Hartung wrote, "frozen in time, using and accepting the same old animal models again and again, often without stringent examination of their validity" (Leist et al., 2008).

According to Dosi (1982) changing the technological paradigm means starting at the base of the problem solving phase. And that is exactly what the community of regulators often pleads for when referring to the need to first unravel the underlying biological mechanism before switching to a new testing model. The animal model incorporates this biological mechanism, even though the modus operandi remains a black box. Nevertheless, it is often felt to be essential for designing a scientifically sound $3 \mathrm{R}$ model to fully understand the underlying biological mechanism.

\subsubsection{Small varieties, big consequences: the problem of diverse risk regulation regimes}

Hood et al. (2001) refer to the meso-level in terms of "risk regulation regimes." These regimes consist of the complex of institutional geography, rules, practices, and ideas associated with the regulation of a particular risk or hazard. Regulatory decision-making is a core activity in these regimes. Instead of defining one regime, the theory on risk regulation regimes emphasizes the existence of diversity in risk regulation, which is a result of the different pressures that lead to regulating the risk. The authors define three main shapers of regulatory content: "the type of risk," "public attitudes," and "organized interests." Hood et al. (2001) state that there is a relationship between public preferences and the regime content, meaning that the way in which society perceives different risks (see landscape level) is reflected in the way these risks are regulated. This might, for example, explain why some risks are highly regulated and others are hardly regulated. ${ }^{12}$ On top of that, risk perception has a cultural element to it, which explains why different countries might regulate the same product in different ways.

These differences can also be observed in the area of safety and quality testing. The political and public demand for safety depends on cultural values leading to different expectations with regard to the levels of safety. The regulatory systems must accommodate these expectations (Richmond, 2002). As a result, every regulatory level developed requirements to deal with these demands, and in the past this frequently happened in a fairly isolated manner. This has led to situations in which requirements for one product differ from one region to the next. In the case of rabies vaccines, for example, it has resulted in multiple varieties of the procedure for potency testing of inactivated vaccines between the different regulatory levels. ${ }^{13,14}$

\footnotetext{
11 Possible technological directions within the boundaries of a technology paradigm.

12 UK vehicle emissions, for example, are highly regulated, while smoking tends to be less heavily regulated although it is assumed to be a much bigger killer. And the regulation of pesticide residues in drinking water in the UK is highly risk averse while the regulation of cancer risks of the emission of radon gas in houses shows a high level of risk tolerance (Hood et al., 2001).

13 i.e., the European Pharmacopoeia, the World Health Organization, the World Organization for Animal Health (OIE), and the US Code of Federal Regulations.

14 These varieties concern, among other things, the number of tests required, the number of mice to be used, the number of dilutions to be administered, and the different criteria for evaluation of the test, i.e., death or signs of rabies and the survival rate (Bruckner et al., 2003).
} 
But even if the regulatory requirements are the same, as is the case for most pharmaceuticals and biologicals (e.g., vaccines) within Europe, regulatory variability can occur for those products that follow the decentral route, which means that they are assessed at the level of individual Member States. Countries can then make use of the discretionary space that is offered by the regulatory requirements. This leads to divergent ways of interpretation and implementation of the requirements by regulatory agencies (Bakker and van Waarden, 1999).

Dissimilar regulatory requirements and a diverse interpretation of requirements exact a heavy toll on innovations like 3R models and their acceptance. Manufacturers increasingly operate in international markets and face the difficult task of complying with this diversity. The use of $3 \mathrm{R}$ models by manufacturers for regulatory purposes depends to a large extent on the level of regulatory acceptance achieved. In case of diversity, manufacturers will either anticipate the strictest set of requirements or will even execute all the different tests requested by the different regulatory regimes. One manufacturer of biologicals pointed out that it is not uncommon for them to conduct five or even more different test protocols for the same product to comply with all these different regulations, with all due effects in terms of time, costs, and numbers of animals used.

\section{The need for harmonization}

Regulatory acceptance of a 3R model at one specific geographical level is therefore insufficient. Industries will hang on to the conventional animal model as long as they still have to conduct these tests for one regulatory authority. The most favorable situation is regulatory acceptance of a $3 \mathrm{R}$ method at the highest possible geographical level. As a result, industry is lobbying very actively for harmonization of legislation. If an alternative, for example, is accepted by the OECD for chemicals or at the ICH (International Cooperation on Harmonisation of Technical Requirements for Registration of Medicinal Products) level for veterinary pharmaceuticals, the connected geographical regions are automatically taken on board. This makes harmonization one of the dominant prerequisites for regulatory acceptance and use of $3 R$ models.

At the same time, harmonization is a very lengthy and difficult process. To give an example: to change an OECD test protocol, all 30 Member States must agree to the alterations. This consensus approach means that rapid and dramatic alterations in the recommended OECD policy are unlikely to occur (Rudacille, 1999).

"At least for regulatory toxicity testing, the global frame and network are given by institutions such as OECD, ICH, and alike. Due to the necessity of global consent of states, organizations, and stakeholders, the time gap between availability of a novel alternative test method and its acceptance by authorities and implementation thereafter is widening." (Garthoff, 2005)

Furthermore, harmonization is said to suffer from the "Not Invented Here syndrome," which means that the parties involved are willing to harmonize as long as their own criteria are accepted as the standard. And finally, frontrunners - industry, regulatory authorities, or academia - that are already using high standards in the area of the 3Rs fear that, by harmonizing the requirements internationally, standards might be lowered to the common denominator (Busfield, 2006).

All in all, harmonization is considered to be very important for the acceptance and use of $3 \mathrm{R}$ models, but is at the same time a very difficult process, dominated by cultural differences, psychological barriers, and competition, both scientific and economic. Nevertheless, harmonization is high on the political agenda, and efforts such as the International Conference on Harmonization of Technical Requirements for Registration of Pharmaceuticals for Human Use (ICH) have already booked their first successes (Majone, 2010).

\subsubsection{Informational asymmetry between regulators and industry}

Another factor at the regime level is the information exchange between regulator and regulatee (regulated industry). The regulatee often has an information advantage, having in depth knowledge of the technical aspects regarding the product and the variety of relevant legal requirements (Abraham, 1995; De Bruijn and Koopmans, 2005; Dupree et al., 2007). Regulators may often have less $3 \mathrm{R}$ knowledge in comparison to industry, since industry already often uses these methods in the $R \& D$ phase or in the production process. On top of that, a $3 R$ method is sometimes custom-made for a particular production process, meaning that only the manufacturer of that product is acquainted with the specificities of the model used. Consequently, regulatory authorities face difficulties judging the alternative method on its merits, leaving them to a certain extent dependent on the information provided by the manufacturer. This phenomenon is also referred to as "informational asymmetry" (Heritier, 2001).

The area of risk assessment of products is very complex, and technical expertise is a crucial factor in the decision-making process of whether or not to implement a $3 \mathrm{R}$ method in safety and efficacy testing. The informational asymmetry therefore makes regulators cautious in adopting test models they are not completely familiar with.

On the other hand, regulatees depend on decisions made by regulators regarding their product. Manufacturers often feel they are being left in the dark regarding the precise criteria regulators will use in judging whether a $3 \mathrm{R}$ model will be accepted for safety or quality testing purposes. This might be the result of limited communication between regulators and developers of alternative methods, which leads to the development of $3 \mathrm{R}$ models that fail to take regulatory needs sufficiently into account. To solve this problem, it is often recommended that regulators should be involved at the various stages of the validation process of a $3 \mathrm{R}$ model to discuss the regulatory criteria the model has to meet (EPAA, 2007; Bottini et al., 2008). All in all, the regulator-regulatee interaction is one of close interdependence (Dupree et al., 2007).

A consequence of the informational asymmetry and limited communication is that regulators lean towards relying on their existing knowledge and on the level of scientific consensus concerning animal experiments and alternatives. Without the scientific backing it is a precarious decision to incorporate an 
alternative into the product assessment procedure. This process of reaching scientific consensus, by the very nature of scientific methodologies, is difficult to achieve and takes a long time. And so are the changes in favor of $3 \mathrm{R}$ models.

An important development in this respect is the increasing number of efforts to erect forums where stakeholders from both regulatory authorities and industry can discuss in a neutral setting the pros and cons of the available models - both 3R and animal models. This type of interaction and communication is important to pave the way towards regulatory acceptance and use of $3 \mathrm{R}$ models.

\section{Data sharing as a possible solution}

A possible way of dealing with the informational asymmetry is by sharing research data. As one respondent put it: "There are databases full of information, but these are not accessible because the industry owns them. A lot of the data concerning newly developed methods stay within the walls of the company." Sharing data can help regulators build up experience with and thereby gain trust in the $3 \mathrm{R}$ models used by the regulatees. A further step would be to share data with other manufacturers. This could have a major effect on reducing the number of duplicated tests.

Data sharing is already considered one of the core principles in the REACH Regulation ${ }^{15}$, and it allows companies to reduce costs and avoid unnecessary testing on vertebrate animals. To meet this requirement the chemical industry has made a start in setting up a network to share knowledge and data. It must be noted, however, that in practice this element needs further improvement, since registrants repeatedly fail to consider their obligations for sharing data or do not come to an agreement with other potential registrants on the sharing of these data (ECHA, 2010).

\subsubsection{Transition costs}

Decisions made by manufacturers are the product of continuous cost-benefit analyses to weigh what the costs or profit of an investment/innovation will be. Profit here does not solely refer to economic profit, but might also mean reputational or scientific profit. MacLachlan (1994) argues that product safety is very important to industry due to the fact that this "responsible behaviour is vital for continued business success." Olson stipulates the importance of the speed and the costs of the process from R\&D to market approval. The average time required, for instance, for the pharmaceutical industry to develop, test, and gain approval of a new prescription drug in the US is about 12 to 15 years (Olson, 1997; MacLachlan, 1994). Estimates about the cost of developing a new drug vary widely, from $\$ 800$ million to nearly $\$ 2$ billion per drug (DiMasi et al., 2003). ${ }^{16}$ After the development and thorough testing of the product, the Food and Drug Administration generally takes another one to four years to review the application and grant market approval. The length of this regulatory procedure erodes the patent protection and is said to be an important disincentive to innovation, since every change in the production process requires a new regulatory approval (Jaffe, 1994). In short, speed of research, development, and registration is a very important factor for industries such as pharmaceutical companies. And every innovation that can speed up this process will be embraced, whereas every innovation that slows it down will be discarded.

Time and costs are therefore important arguments for the industry in the choice of a testing model. If industry foresees any economic or regulatory hurdle in using a new model it will most likely stick to the conventional method. But the cost aspect can also work in favor of 3R methods, since these methods are often quicker and less expensive than the methods they supersede (Richmond, 2002). In the best scenario, cost efficiency and reducing animal testing converge. In this respect the large-scale industrial lobby to influence REACH is frequently referred to. Here the industry's lobby gave counterweight to the call for more testing, since the chemical industry has no interest in regulations that further increase the number of required tests.

According to several respondents, another reason for stakeholders to adhere to existing test methodology is to protect their "return on investment." For example, this makes research laboratories within different institutions reluctant to disrupt the existing testing infrastructure, which often still relies on animal models. And finally, respondents pointed out that research departments of regulatory authorities, industry, and academia do not want to run the risk of losing their existing knowledge of/ and experience with animal testing and thereby fall behind or even become dependent of others in the field. Therefore, they anxiously hold on to existing practices.

In short, several economic motives can be identified that are perceived to influence the acceptance and use of $3 \mathrm{R}$ models. However, it can be questioned whether these motives play a decisive role in the actual process of acceptance and use of $3 R$ models for regulatory purposes. Vermeulen (2011) argues that innovations that are interesting from an economic perspective also face difficulties in breaking through due to the existing interests and the strong convictions of the stakeholders within a sector.

\subsection{Developments at the macro-level of the socio- technical landscape}

The socio-technical landscape relates to material and immaterial elements at the macro-level, such as the political culture, social values, world views, the macro-economy, demography, and the natural environment (Kemp, 2010). The socio-technical regimes and niches are both influenced by developments at the macro-level. The landscape is the hardest element of the three to change (Geels, 2002).

\footnotetext{
15 European Community Regulation on chemicals which deals with the Registration, Evaluation, Authorization and Restriction of Chemical substances. The new law entered into force on June 1, 2007.

16 It must be noted that these high estimations are criticized by some as being in the interest of industry to keep its estimations as high as possible (Light and Warburton, 2011).
} 
Three societal developments are distinguished here that influence the transitions towards the regulatory acceptance of $3 \mathrm{R}$ models, i.e., the risk society (see 3.3.1), the concern for animal welfare (see 3.3.2), and the culture of litigation (see 3.3.3).

\subsubsection{The risk society...}

Many innovations offer high scientific and societal potential on the one hand and scientific uncertainties and health and welfare concerns on the other. The society that has to cope with such technologies is also referred to as the "risk society." This concept was introduced into sociology by Ulrich Beck (1992) and was later adopted by sociologist Anthony Giddens. The latter has described the risk society as follows:

“... a society where we increasingly live on a high techno-

logical frontier which no one completely understands...

It is a society that is increasingly preoccupied with the

future and with safety, which generates the notion of risk'

(Giddens, 1999: 3).

The problem of these "manufactured risks," as Giddens calls them, is that society has relatively little experience with them and thereby little knowledge of the actual risks they pose (Giddens, 1999). As a result, the risks have to be assessed by experts.

Societies' response to the unpredictability of manufactured risks is to try to prevent, minimize, and channel them, for example, by delegating this task to regulatory authorities charged with controlling possible negative side-effects of industrial activity (Malyshev, 2006). As a result, regulators have to deal with a great number of responsibilities on the one hand and uncertainties on the other. The regulators' reaction to this thorny combination is likely to be one of sticking to the routines they are familiar with. Or as Breyer put it:

"Rules - or procedures - become frozen in place and cannot readily adapt to changing scientific knowledge". (Breyer, 1993: 49)

A first and very important influence on regulatory acceptance and use of $3 \mathrm{R}$ models at the landscape level is this striving of modern society for risk minimization, with the precautionary principle as leitmotiv. The precautionary principle, which recommends to "err on the side of preservation" (Barrieu and Sinclair-Desgagne, 2003), has clear consequences for the way in which new technologies/products are adopted.

According to Breyer, the public perception of a certain risk influences the politician's action and subsequently the regulatory reaction to it (Breyer, 1993). Both the public's perception and the politician's response influence the regulator's decisions in dealing with certain risks, despite the fact that the public and politicians are unlikely to understand the complexity of the matter. The higher the presumed risk of a new technique or product, the more stringently it will be regulated, even though the perceived risk does not always correspond with the actual hazard.
Risk perception is related to several factors, such as dread, controllability, voluntariness, and observability, with the dread factor as the most influential one. The higher the dread factor of a product, the higher its perceived risk is, and the louder the call for strict regulations will be (Slovic et al., 1984). Pharmaceuticals and vaccines, for example, are categorized as belonging to the class of "unavoidable, unsafe products," which offer desired benefits but are not without risk (Jaffe, 1994). A certain level of risk is accepted by the public when it comes to pharmaceuticals, but this level is much lower for vaccines, which are administrated to young and healthy children. ${ }^{17}$ Industrial chemicals are another product group relevant in terms of regulatory testing. The accepted risk for this group of products is, as a result of the high dread factor and the involuntariness of being exposed to these compounds, close to zero. This has had its effect on the regulatory requirements for different groups of chemicals that are very strict and aim for zero or negligible risk levels (Kasamatsu and Kohda, 2006).

The consequence of this societal priority of risk minimization is that the use of animals for safety and efficacy testing of new products has increased significantly over the past forty years. However, the focus on risk avoidance not only increases the number of animals used, it also is detrimental to the acceptance of alternative test models. In response to society's risk aversion, alternative methods often are not accepted by regulators. The alternative methods must be proven three times over before they are perceived to be as valid, sensitive, and specific as conventional methods. As has been discussed before, these are characteristics to which conventional methods do not always adhere. And as long as a 3R model is not widely accepted by regulatory authorities, it will not be used on a broad scale by manufacturers to meet with regulatory requirements.

\subsection{2 ...versus the concern for animal welfare}

In Western society another development also can be observed: the growing concern about the welfare of animals and the potential for animal suffering in product testing. Within Europe this concern has been translated into a legislative act, Directive 2010/63/EU, for the protection of laboratory animals for scientific purposes (European Commission, 2010). This horizontal legislation which states that alternative models should be used wherever possible, must be taken into account by vertical or sectorial product legislation. ${ }^{18}$ Some vertical legislation already explicitly refers to this horizontal legislation, but a lot can still be gained in this area. For instance, there generally is little interaction between the EU committees drafting this vertical legislation and those that develop the horizontal animal welfare legislation (De Leeuw, 2004; Schiffelers et al., 2007). The result is that sectorial legislation, when revised, continues to require animal tests, even after validated alternatives have become available (Schiffelers et al., 2007). Furthermore, the growing attention to animal welfare cannot outweigh the con-

\footnotetext{
17 Due to the complex production process, vaccine lots can vary in quality and consequently in safety and efficacy.

18 Horizontal legislation pertains to animal experimentation and multilateral agreements in general. Vertical or sectorial legislation regulates the activities of a particular sector (Schiffelers et al., 2007).
} 
cerns related to protecting human health, in the sense that the quality of products such as pharmaceuticals may never be compromised. ${ }^{19}$

\subsubsection{Culture of litigation}

Together with the development of risk minimization, the culture of litigation is gaining terrain in contemporary society. Regulatory authorities face high demands for consumer safety and risk minimization, and they are expected to take this into account when implementing policies. This means that they bear a heavy responsibility and that they are particularly susceptible to a negative sense of responsibility. Or as one representative from a Dutch regulatory authority put it:

"If anything goes wrong, we will be held accountable."

Every change in the way substances are assessed is to some extent risky. No one can guarantee that a change can be implemented without compromising the quality of the assessment procedure of products (De Leeuw, 2004). A change in regulation and its implementation is therefore often seen as a potential liability. As a result, both industry and regulators generally take a fairly passive approach to innovating product registration and release procedures. This point is illustrated by the comment of a civil servant of the European Commission (Schiffelers et al., 2005: 37):

"It's better not to change ten times, than to make nine changes for the better and one for the worse."

As Michael Power put it in his inaugural speech:

"An age of 'new risk management' has dawned in corporate governance, sparked by high-profile business failures and accidents." (Hood, 2002:15)

The potential threat of such incidents as the often described thalidomide disaster in the 1960's continuously influences manufacturers and regulators to be very cautious in the decisions they make (Olson, 1997; Carpenter, 2010). At first glance this defensive risk management seems to be in line with what government and regulators are there for, namely protecting individuals from "suffering." But a strong focus on avoiding blame and liability may well have the opposite effect (Hood, 2002).

"...The concern for blame prevention seems to be leading to protocolization and risk assessment inflation to establish procedural alibis as a form of bureaucratic insurance." (Hood et al., 2001: 179)

Politicians and regulators mainly concerned with the avoidance of (political) blame over hazard and safety might end up hardly changing anything (Hood, 2002), even if the current situation is far from optimal. ${ }^{20}$

This protocolization can also be observed in the area of regulatory testing. Here the fear of litigation leads to adhering to trusted methods and a rigid interpretation of test protocols. This is also referred to as the "tick box approach," a strict way of holding on to every test described in the protocols without taking a critical look at the relevance of the tests, the necessity of conducting all these tests, or the possibility of using an alternative testing model. It should be noted here, however, that the level at which this "tick box approach" is applied differs according to product group and regulatory authority. Some product sectors, such as pesticides, are notorious for their tick box approach ${ }^{21}$, whereas the areas of pharmaceuticals and biologicals are said to be more flexible when it comes to the interpretation of the test guidelines. But in the areas where there is more discretionary space to choose the method best suitable for the job, the existing technologies also give the highest assurance with regard to liability. Decisions then are based mainly on custom and practice, rather than on an informed science-driven selection of the method most likely to provide the most relevant result (Richmond, 2002). And for fear that authorities might reject certain results, regulatory affairs departments of industry are said to take pre-emptive action by anticipating the most strict registration requirements. It will be clear that this kind of risk avoidance obstructs the risk taking that is intrinsic to innovation and thereby deters the development and acceptance of new technologies, such as $3 \mathrm{R}$ models.

\section{Creating a breakthrough: towards critical junctures}

As mentioned Geels states that "radically new technologies have a hard time breaking through" (Geels, 2002: 1258). This is precisely what can be observed in the field of regulatory acceptance and use of $3 \mathrm{R}$ models where several models have been available for decades but still haven't been able to become part of the existing regulatory regime. However, history has proven that very firm configurations also can change (Geels, 2002). For this purpose, it is important to comprehend which variables influence the process of acceptance and use and in what ways.

In the previous section, a wide range of variables was defined that are considered to influence the transformation from the existing test regimes to the acceptance and use of 3R models. Some of these variables are perceived mainly to obstruct, whereas others are considered to drive the process of acceptance and use. These variables and the nature of their influence are summarized in the "3R Acceptance Model" (see Fig. 2).

For this model an adjusted version of the fishbone diagram of Ishikawa is used (Nathans, 1997). This diagram offers the opportunity to get to the roots of a problem that has many possible causes. The original model is adjusted in two ways. First, the model presented here not only presents the different influencing variables, it also distinguishes which are considered to be drivers and which barriers. Furthermore, a distinction is

\footnotetext{
${ }^{19}$ An opinion poll in the Netherlands underlines this: two-thirds of the population is of the opinion that animal tests for medical purposes are acceptable (Intomart GfK, 2004).

20 The phenomenon of injury litigation, for example, has become a major risk in the US and has had a chilling effect on innovation in many American industries (MacLachlan, 1994).

21 http://www.hslf.org/epa-animal-testing/
} 


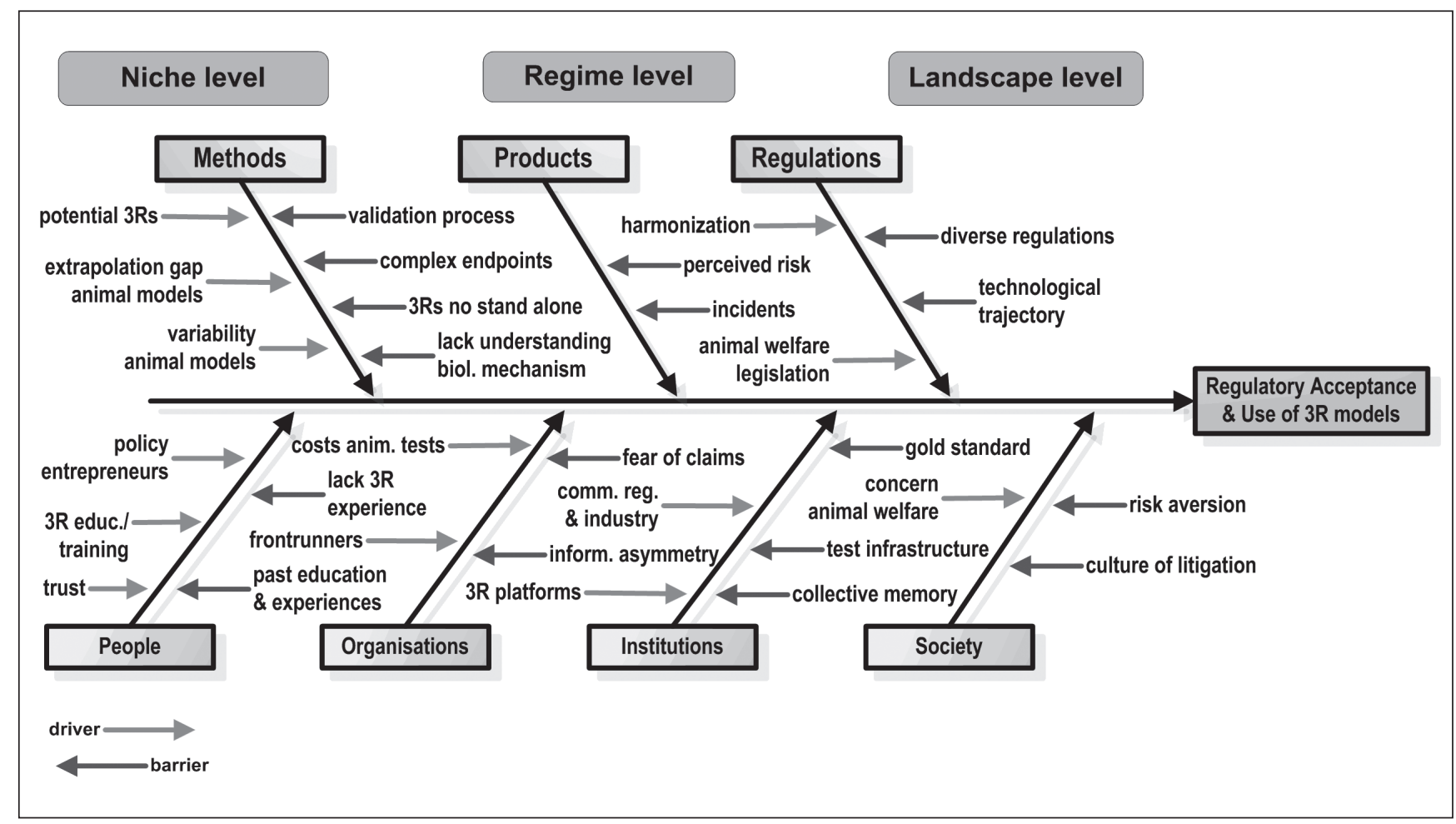

Fig. 2: The 3R acceptance model

made between the niche (micro-), regime (meso-), and landscape (macro-) level, as used in the multilevel perspective. At the niche level factors concerning people and methods can be found. The regime level consists of factors connected to products, organizations, institutions, and regulations. The landscape level covers the broader societal factors.

This model offers a tool to understanding the complex reality in which the acceptance and use of $3 \mathrm{R}$ models takes place. To stimulate a breakthrough it is important to make an additional distinction between the more pliable and the rigid factors (Ellemers, 1976). As described, the process of technology acceptance is determined by the influence of variables at the niche, the regime and the landscape level. In general, it can be stated that the higher the level at which a variable is situated, the stronger this variable is, i.e., the more difficult it is to manipulate the variable. A variable such as the risk society exerts a substantial influence on the acceptance of $3 \mathrm{R}$ models, but is at the same time a factor that is very hard to counter. The more pliable factors, as a rule, can be found at the lower levels, i.e., the niche and partly at the regime level. Variables like education and training, communication and dissemination of successes, and facilitating and stimulating frontrunners are all at these lower levels and are very important ways of stimulating a breakthrough. As mentioned, the variables at the landscape and partly at the regime level are considered to be the stronger variables. However, this does not mean that change cannot occur or be stimulated at these levels, for example, by keeping animal welfare and the need for harmonization high on the political agenda.
Technology acceptance is a process of shifting congregations or "reweaving the elements," as Geels puts it (Geels, 2002: 1259). Changes in one element can elicit changes in other elements, and alignment of these different elements can create a shift in the sociotechnical regime. This occurs, for example, if a development in a niche falls together with a change or request for change in the regime and within the sociotechnical landscape, creating a potential breakthrough or a "critical juncture."

Critical junctures occur when existing institutions are challenged or become instable (Krapohl, 2008), and they can be of endogenous or exogenous nature (Bakker, 2001). Endogenous critical junctures start from within the sociotechnical regime and can arise if the existing routines fail to meet the expectations, for example, animal models that show high variability in test results and difficulties in terms of the extrapolation from the animal results to human beings. Exogenous critical junctures are the product of developments outside the regime. These might be due to shifts in the landscape, for example, a growing concern about animal welfare, or by the linkage of several new technological developments, i.e., niche accumulation at the microlevel, which can occur if a combination of $3 \mathrm{R}$ models proves to be a solid answer to the problems in the existing regime.

According to the theory on technology transitions, bottlenecks for new technologies can be solved more easily if they are linked with existing technologies, starting a symbiotic relation. This means that technology transition most often is an incremental process in which new regimes gradually grow out of old ones (Geels, 2002). Therefore 3R models that build upon 
an existing animal model, i.e., reduction and refinement models, are expected to face fewer difficulties in terms of acceptance compared to models that fully replace the animal model.

According to Dosi the breakthrough of technological innovations also can be stimulated by risk taking actors that are ready to try different solutions (Dosi, 1982): an entrepreneur with socalled "Schumpeterian" features. ${ }^{22}$ This can be an individual or organization that is willing to take a certain risk, keep the discussion alive, and keep the topic of the 3 Rs high on the agenda. These policy entrepreneurs, as Kingdon calls them, are skilled at coupling problems, solutions, and policies, and they can thereby respond rightly to critical junctures or policy windows in Kingdon's terminology (Kingdon, 1995; Schiffelers et al., 2005). A comparable concept is that of the boundary spanner who is characterized by his ability to connect and mediate between the parties and their different interests and who knows how to cross cultural/organizational borders (Williams, 2002). They facilitate mutual communication and understanding. These intermediates can come from regulatory authorities, industry, academia, and NGO's. Ideally, they are trusted and fairly neutral parties with a high level of knowledge of the specific problems. They can facilitate stakeholders in recognizing and taking a proactive approach towards potential critical junctures.

Alignments towards critical junctures are already taking place in some cases, in the sense that there is increasing agreement on the flaws of certain animal models and the scientific potential of the $3 \mathrm{R}$ models that could replace them. In these cases several boundary spanners or policy entrepreneurs can be observed who put a lot of energy into bringing the parties together to take the discussion a step further.

\section{Conclusions and recommendations}

We are living in a risk averse society, which means that our striving for risk minimization is a fundamental element of our society. A common response of most industrialized countries to the intrinsic uncertainties of new technologies is to try to minimize their potential negative side effects. This is operationalized primarily by setting up risk regimes of regulatory authorities, rules, and regulations to minimize the possible adverse effects of products like pharmaceuticals and chemicals. In terms of technology transitions, the risk averse society is a very important feature of the landscape in which new technologies like $3 \mathrm{R}$ models are being developed. This risk aversion strongly influences the way stakeholders within the regulatory regime, like regulatory authorities and manufacturers of products, look upon new technologies such as $3 \mathrm{R}$ models. The risk aversion is amplified by public and political pressure, incidents, the culture of litigation, and the informational asymmetry between regulators and regulatees.
As a result, the sociotechnical regime of product regulation still depends largely on animal models, meaning that the current knowledge, the research infrastructure, and risk assessment practices are dominated by regulatory animal testing. On the one hand, the regime faces pressure from social groups that ask for safe products and the reduction of animal testing simultaneously and on the other hand from niche developments consisting of $3 \mathrm{R}$ methods that challenge the conventional ways of testing. In this paper, an overview of barriers and drivers has been presented using the multilevel perspective on technology transitions. The wide variety of drivers and barriers in the process of regulatory acceptance and use of $3 \mathrm{R}$ models ${ }^{23}$ reflects the complexity of the matter. Even more so, because the combination of factors might differ per product sector and sometimes even per product.

$3 \mathrm{R}$ methods remain relatively new compared to the standard testing routines and practices. As a result, stakeholders have less experience with them, leading to a lack of trust as to whether they can offer levels of safety comparable to the animal model. As long as $3 \mathrm{R}$ models suffer from this lack of trust they will have a hard time breaking through.

The inertia 3R models have been confronted with ever since their introduction by Russell and Burch in 1959 is a phenomenon that can be observed in technology transitions in general and is a result of the deeply rooted collective memory of the stakeholders. By definition, innovation is uncertain and controversial until it is accepted as the norm.

All innovations start with the willingness to accept failure (MacLachlan, 1994). Regulatory authorities and industries acknowledge that there is a lack of trust and express the need to take a "leap of faith" in those cases where 3R methods have been thoroughly tested and validated but are still not accepted. In the area of product regulation, however, failure can have big consequences. Thus the inertia in the situation of $3 \mathrm{R}$ models is aggravated by the context in which these models are used, i.e., to guarantee the safety and quality of products that are looked upon as a risk to human health or the environment. For this reason, it must also be accepted that such institutional changes take their time and regulatory acceptance of $3 R$ methods is most likely to occur as an incremental process, i.e., no change in terms of radical developments but new test regimes that gradually grow out of old ones (Geels, 2002). Many respondents even warn of discarding the animal model at too early a stage. They indicate that a "stand-alone" situation, of either in vivo or in vitro methods, is in most situations neither feasible nor desirable (Schiffelers et al., 2007). This is fully in line with Vermeulen, who states that it's not only impossible to eradicate the old institutions, it is also undesirable (Vermeulen, 2011). A well-considered combination of both types of testing, therefore, is believed to be the best feasible scenario. It is important, then, not to think in revolutions but rather in terms of evolutions.

22 Joseph Alois Schumpeter was an Austrian-American economist who was probably the first to look at the important role of entrepreneurs. Schumpeter argued that the innovation and technological change of a nation comes from the entrepreneurs, or wild spirits.

${ }^{23}$ As mentioned earlier in this paper, regulatory use is seen as a function of regulatory acceptance, in which the level of acceptance highly determines the level of regulatory use. Without regulatory acceptance, regulatory use will only occur sporadically. 
Evolutions require thinking in terms of small but on-going steps. Only intense and continuous forms of communication, dissemination, and education can help to overcome the inertia that had already been observed by Russell and Burch in 1959 (see quotation in the introduction). This means, for example, that an exhaustive approach to communication is required between stakeholders, such as regulatory authorities, industry, and academia about $3 \mathrm{R}$ developments and the chances they offer for regulatory testing. More specifically, communication between regulatory authorities and manufacturers should be intensified to level off the informational asymmetry between these parties. And sharing test data will help regulatory authorities to build up experience with the specific $3 \mathrm{R}$ models and will facilitate the process of building new experiences, rules, practices, and routines and thereby slowly change the existing institutions. And in the end, such a multitude of relatively small steps can lead to a landslide in favor of the 3 Rs.

\section{References}

Abraham, J. (1995). Science, Politics and the Pharmaceutical Industry: Controversy and Bias in Drug Regulation. London, UK: Routledge.

Anon. (2010). Sixth Report from the Commission to the Council and the European Parliament on the Statistics on the number of animals used for experimental and other scientific purposes in the member states of the European Union COM (2010) 511 final. Brussels, Belgium: EC.

Bakker, W. and van Waarden, F. (eds.) (1999). Ruimte rond regels: stijlen van regulering en beleidsuitvoering vergeleken. Amsterdam, The Netherlands: Boom.

Bakker, W. (2001). Sturen op de tijstroom: Onderwijs voor werkende jongeren en beleid tussen economie en ontplooiing, 1945-1995. The Netherlands: Thela Thesis.

Barrieu, P. and Sinclair-Desgagne, B. (2003). The paradox of precaution, Scientific series, Cirano, Centre interuniversitaire de recherché en analyse des organisations. Montreal, Canada.

Beck, U. (1992). The Risk Society, Towards a New Modernity. London, UK: Sage Publications Ltd.

Bottini, A., Alepee, A., Phillips, B., et al. (2008). Optimization of the post-validation process, the report and recommendations of ECVAM workshop 67a. ATLA 36, 353-366.

Breyer, S. G. (1993). Breaking the Vicious Circle: toward effective risk regulation. London, UK: Harvard University Press.

Bruckner, L., Cussler, K., Halder, M., et al . (2003). Three Rs approaches in the quality control of inactivated rabies vaccines. ATLA 31, 429-454.

Busfield, J. (2006). Pills, power, people: sociological understanding of the pharmaceutical industry. Sociology 40, 297-314.

Carpenter, D. (2010). Reputation and Power: Organizational Image and Pharmaceutical Regulation at the FDA. Princeton, USA: Princeton University Press.

De Bruijn,H. and Koopmans, M.(2005). Enforcing the law: Strategies used by regulates and enforcement officials. PaperECPR. http://regulation.upf.edu/index.php?id=budapest_2005

De Leeuw, W. (2004). De ethische toetsing van dierproeven: wat heeft Europa ons te bieden. In J. Swart, J. Wolters, and
H. Zwart (eds.), DEC's in Discussie: de Beoordeling van Dierproeven in Nederland. Budel, The Netherlands: Damon.

DiMasi, J. A., Hansen, R. W., and Grabowski, H. (2003). The price of innovation: new estimates of drug development costs. $J$ Health Econ 22, 151-185.

Dosi, G. (1982). Technological paradigms and technological trajectories, a suggested interpretation of the determinants and directions of technical change. Research Policy 11, 147-162

Dupree, M., Etienne, J., and Lecoze, J. C. (2007). The regulator-regulatee interaction: insights taken from a high risk business firm. $2^{\text {nd }}$ Annual Cambridge Conference on regulation, Inspection \& Improvement, Cambridge. http://www.cbr.cam. ac.uk/pdf/Dupre_et_al_Paper.pdf

ECHA (2010). Evaluation under REACH, Progress Report 2010. ECHA-11-R-001-EN, Helsinki, Finland: European Chemicals Agency.

Ellemers, J. E. (1976). Veel kunnen verklaren of iets kunnen veranderen: krachtige versus manipuleerbare variabelen. Beleid en Maatschappij 3, 284.

EPAA (2007). Annual Conference of the EPAA. http://www. epaa.eu.com

European Commission (2010). Directive 2010/63/EU of the European Parliament and of the Council of 22 September 2010 on the protection of animals used for scientific purposes. http://eurlex .europa.eu/LexUriServ/LexUriServ.do?uri=OJ:L:2 010:276:0033:0079:EN:PDF

Freriks, A., van der Meulen, B., van den Belt, H., et al. (2005). Noodzakelijk kwaad, Evaluatie Wet op de dierproeven. http:// www.nvdec.nl/page8/page1/files/Evaluatie\%20WOD.pdf

Garthoff, B. (2005). Alternatives to animal experimentation: the regulatory background. Toxicol Appl Pharmacol 207, Suppl 2, 388-392.

Geels, F. and Kemp, R. (2000). Transities vanuit sociotechnisch perspectief, report for the study "Transities en Transitiemanagement" of ICIS and MERIT for the Department of Environment for the NMP-4, Okt 2000, UT, Enschede en MERIT, Maastricht. http://kemp.unu-merit.nl/pdf/geelskemp.pdf

Geels, F. W. (2002). Technological transitions as evolutionary configuration processes: a multi-level perspective and a case study. Research Policy 31, 1257-1274.

Geels, F. W. (2006). Multi-level perspective on system innovation: relevance for industrial transformation. In X. Olshoorn and A. J. Wieczorek (eds.), Understanding Industrial Transformation: Views from Different Disciplines (163-186). The Netherlands: Springer.

Giddens, A. (1999). Risk and responsibility. The Modern Law Review 62, 1-10.

Heritier, A. (2001). Regulator-regulatee interaction in the Liberalized Utilities: Access and Contract Compliance in the Rail Sector Max-Planck-Projectgruppe, Recht der Gemeinschaftsgüter, Bonn 2001/12. http://www.coll.mpg.de/publications/ regulator-regulatee-interaction-liberalized-utilities

Hood, C., Rothstein, H., and Baldwin, R. (2001). The Government of Risk: Understanding Risk Regulation Regimes. New York, USA: Oxford University Press.

Hood, C. (2002). The risk game and the blame game. Government and Opposition 37, 15-37. 
Intomart GfK (2004). Publieke opinie over dierproeven in Nederland, a study commissioned by the Dutch Society for the Protection of Animals, Hilversum, The Netherlands.

Jaffe, M. E. (1994). Regulation, litigation and innovation in the pharmaceutical industry: An equation for safety. In J. R. Hunziker and T. O. Jones (eds.), Product Liability and Innovation; Managing Risk in an Uncertain Environment (120-128). Washington D.C., USA: The National Academies Press.

Kasamatsu, T. and Kohda, K. (2006). Commentary: Balancing risks. Regul Toxicol Pharmacol 46, 100-104.

Kemp, R. (2010). The Dutch Energy transition approach. International Economics and Economical Policy 7, 291-316.

Kingdon, J. W. (1995). Agenda's, Alternatives and Public Policies ( $2^{\text {nd }}$ ed). New York, USA: Longman Pub. Group.

Krämer, B., Bruckner, L., Daas, A., and Milne, C. (2010). Collaborative study for validation of a serological potency assay for rabies vaccine (inactivated) for veterinary use. Pharmeur Bio Sci Notes, 37-55.

Krapohl, S. (2008). Risk Regulation in the Single Market; The Governance of Pharmaceuticals and Foodstuffs in the European Union. Palgrave Studies in European Union Politics, Hampshire, UK: Palgrave Macmillan.

Leist, M., Hartung, T., and Nicotera, P. (2008). The dawning of a new age of toxicology, ALTEX 25, 102.

Liebsch, M. and Spielmann, H. (2002). Currently available in vitro methods used in the regulatory toxicology. Toxicol Lett 127, 127-134.

Light, D. W. and Warburton, R. (2011). Demythologizing the high costs of pharmaceutical research. BioSocieties, doi:10.1057/biosoc. 2010.40

Majone, G. (2010). Foundations of risk regulation: Science, decision-making, policy learning and institutional reform. EJRR 1, 5-19.

Malyshev, N. (2006). Regulatory policy: OECD experience and evidence. Oxf Rev Econ Pol 22, 274-299.

MacLachlan, A. (1994). The chemical industry: Risk management in Today's Product liability Environment. In J. R. Hunziker and T. O. Jones, Product Liability and innovation; Managing Risk in an Uncertain Environment. Washington DC, USA: The National Academy Press.

Metz, B., Hendriksen, C., Jiskoot, W., and Kersten, G. (2002). Reduction of animal use in human vaccine quality control: opportunities and problems, Vaccine 20, 2411-2430.

Nathans, H. (1997). Adviseren als tweede beroep, resultaat bereiken als adviseur, herziene druk. Deventer, The Netherlands: Kluwer bedrijfsinformatie.

NIEHS (1997). Validation and regulatory acceptance of toxicological test methods: A Report of the ad hoc Interagency Coordinating Committee on the Validation of Alternative Methods. NIH Publication No. 97-3981, NIEHS, USA.

Olson, M. K. (1997). Firm characteristics and the speed of FDA approval. JEMS 6, 377-401.

Richmond, J. (2002). Refinement, reduction, and replacement of animal use for regulatory testing: Future improvements and implementation within the regulatory framework. ILAR
J V43, Suppl. Regulatory Testing and Animal Welfare. http:// dels-old.nas.edu/ilar_n/ilarjournal/43_supp/v43supRichmond.shtml

Rip, A. and Kemp, R. (1996). 'Towards a Theory of Socio-Technical Change', mimeo UT, report prepared for Batelle Pacific Northwest Laboratories, Washington, D.C. An edited version has been published as book chapter, 'Technological Change' in S. Rayner and E. L. Malone (eds.) (1998), Human Choice and Climate Change. An International Assessment (327-400, Vol. 2). Washington D.C., USA: Battelle Press.

Rudacille, D. (1999). Development of alternatives to animal use for safety testing and hazard assessment. http://www. solutions-site.org/node/84

Russel, W. and Burch, R. (1959). The Principles of Humane Experimental Technique. London, UK: Methuen.

Schiffelers, M. J. W. A., Hagelstein, G., Harreman, A., and van der Spek, M. (2005). Regulatory animal testing, Report number: P-UB-2005-10, August 2005.

Schiffelers, M. J. W. A, Blaauboer, B. J., Fentener van Vlissingen, J. M., et al. (2007). Factors stimulating or obstructing the implementation of the $3 \mathrm{Rs}$ in the regulatory process. ALTEX 24, 271-278.

Slovic, P., Fischhoff, B., and Lichtenstein, S. (1984). Behavioural decision theory perspectives on risk and safety. Acta Psychol 56, 183-203.

Spielmann, H. (2000). Would Sisyphus meet the challenges of validation from test development to global regulatory acceptance, In M. Balls, A. M. van Zeller, and M. Halder (eds.), Progress in the Reduction Refinement and Replacement of Animal Experimentation. New York, USA: Elsevier.

Vermeulen, P. (2011). De verankerende organisatie: Een institutioneel perspectief op veranderen en vernieuwen. Den Haag, The Netherlands: Boom Lemma Publishers.

Verwer, C. M, van der Ven, L. T. M., van den Bos, R., and Hendriksen, C. F. M. (2007). Effects of housing conditions on experimental outcome in a reproduction toxicity study. Regul Toxicol Pharmacol 48, 184-193.

Williams, P. (2002). The competent boundary spanner, Public Administration 80, 103-124.

\section{Acknowledgements}

We thank the Doerenkamp-Zbinden Foundation for sponsoring this project.

\section{Correspondence to}

Marie-Jeanne W. A. Schiffelers

Utrecht University School of Governance

Utrecht University

Bijlhouwerstraat 6

35211 ZC Utrecht

The Netherlands

Phone: +31 302539319

e-mail:m.j.w.a.schiffelers@uu.nl 